\title{
Kinetics of Biodegradation of Phenol and p-nitrophenol by Acclimated Activated Sludge
}

\author{
Sam Suat Peng, Ng Si Ling* and Adnan Rohana \\ School of Chemical Sciences, Universiti Sains Malaysia, \\ 11800 USM Pulau Pinang, Malaysia \\ *Corresponding author: slng@usm.my
}

Published online: 25 February 2018

To cite this article: Sam, S. P., Ng, S. L. \& Rohana, A. (2018). Kinetics of biodegradation of phenol and p-nitrophenol by acclimated activated sludge. J. Phys. Sci., 29(Supp. 1), 107-113, https://doi.org/10.21315/jps2018.29.s1.14

To link to this article: https://doi.org/10.21315/jps2018.29.s1.14

\begin{abstract}
The removal of highly toxic phenolic compounds, such as phenol and p-nitrophenol (PNP) from wastewater through biological approach provides a good cleanup strategy in wastewater treatment. It is recognised as an efficient green treatment with relatively low cost in comparison to conventional physicochemical processes. In this present study, activated sludge was acclimated to phenol and PNP, respectively, using sequencing batch reactor (SBR) system. The growth kinetics of both phenol- and PNPacclimated activated sludge were well described by Haldane model. The values of the Haldane kinetic parameters, namely, maximum specific growth rate, $\mu_{\max }$, saturation constant, $K_{s}$, and inhibition constant, $K_{i}$, were found to be 0.4039 and $0.1346 \mathrm{~h}^{-1}, 5.393$ and $110.3 \mathrm{mg} \mathrm{l}^{-1}$, and 550.8 and $63.58 \mathrm{mg} \mathrm{l}^{-1}$, respectively. The smaller ratio of $K_{s} / K_{i}$ for phenol degradation compared to that of PNP biodegradation indicates the higher resistance of phenol-acclimated activated sludge to inhibition by its substrate. The pseudo zeroth-order equation was able to describe the phenol degradation kinetics at different initial concentrations. However, the equation was inadequate for the PNP degradation which was attributed to its higher toxicity compared to phenol.
\end{abstract}

Keywords: Sequencing batch reactor, acclimated activated sludge, phenol and p-nitrophenol biodegradations, kinetics, Haldane model

\section{INTRODUCTION}

Wastewater is a worldwide concern as it presents a major health and environmental management challenge due to the presence of toxic and hazardous pollutants such as phenol and $p$-nitrophenol (PNP). ${ }^{1,2}$ Therefore, it needs to be treated properly 
prior to being discharged to the environment. In contrast to physicochemical methods, biological approaches provide highly reliable and cost-effective treatment for the complete removal of toxic pollutants. ${ }^{3}$ Activated sludge process is one of the biological approaches in treating wastewater using mixed culture. Besides its simple operation, it is very efficient in mineralising toxic organic compound. ${ }^{4}$

It was reported that acclimation process could enhance the ability of activated sludge to achieve complete mineralisation. ${ }^{5,6}$ Complete removals can be achieved without experiencing inhibition at high concentrations of phenol and PNP at 1050 and $500 \mathrm{mg} \mathrm{l}^{-1}$, respectively, using acclimated biomass were reported. ${ }^{5,6}$ In the study by Sam and $\mathrm{Ng}$, phenol biodegradation time was found to decrease from $330-1260 \mathrm{~min}$ to $35-330 \mathrm{~min}$ for initial phenol concentration of $25-250 \mathrm{mg} \mathrm{l}^{-1}$ after the acclimation of activated sludge to the target compound. ${ }^{7}$

Knowledge on biodegradation kinetics of toxic compounds is essential to improve the removal efficiency and process control. The degradation of phenolic compounds has been known to be inhibited by phenolic compounds themselves, especially at high concentrations. ${ }^{1,7}$ Thus, Haldane model is usually used to describe the growth kinetics of microorganism. Biomass growth can be defined as the increase of quantity of cellular constituents and structure which is accompanied by the increment of size and number of cells. It undergoes several phases, namely lag, exponential, stationary and death phases. ${ }^{3}$ In view of the wide range of concentrations of phenolic compounds in industrial wastewaters, the aim of this study is to investigate the growth and biodegradation kinetics of phenol and PNP at increasing concentrations in order to comprehend the effect of inhibition on the growth trends of acclimated activated sludges and thus their biodegradation performance.

\section{EXPERIMENTAL}

\subsection{Culturing and Acclimation of Activated Sludge}

The seed of activated sludge was collected from a local municipal sewage treatment plant at Batu Ferringhi, Penang, Malaysia. It was then cultured using two identical laboratory-scale sequencing batch reactors (SBRs), namely, R-P and R-PNP. Each reactor with the total working volume of 51 was operated with five operational periods of FILL, REACT, SETTLE, DRAW and IDLE with the time ratio of 2: $8: 1: 0.75: 0.25$ for a $24 \mathrm{~h}$ cycle. The reactors were fed with the base mix of the following compositions (in $\mathrm{mg}^{-1}$ ): bacto-peptone (188), sucrose (563), $\mathrm{KH}_{2} \mathrm{PO}_{4}$ (32), $\mathrm{K}_{2} \mathrm{HPO}_{4}(180),\left(\mathrm{NH}_{4}\right)_{2} \mathrm{SO}_{4}$ (212), $\mathrm{NaHCO}_{3}$ (500), $\mathrm{MgSO}_{4}$ (49), $\mathrm{FeCl}_{3} \cdot \mathrm{H}_{2} \mathrm{O}$ (18.8) and $\mathrm{CaCl}_{2}$ (40). A volume of 3.51 of feed solution was added into 
the reactor and equal volume of treated effluent was withdrawn from the reactor during the FILL and DRAW periods, respectively. The sludge age was maintained at 20 days by wasting $250 \mathrm{ml}$ of mixed liquor at the end of the REACT period. The activated sludges were then acclimated to the final acclimation concentration of $200 \mathrm{mg} \mathrm{l}^{-1}$ phenol and $250 \mathrm{mg} \mathrm{l}^{-1}$ PNP, respectively, in reactors R-P and R-PNP, without supplementing sucrose and bacto-peptone. Both acclimated sludges were used in the biodegradation studies once the quasi-steady state was attained, indicated by the constant values of mixed liquor suspended solid (MLSS) of $1110 \pm 50$ and $600 \pm 50 \mathrm{mg} \mathrm{l}^{-1}$ for R-P and R-PNP, respectively.

\subsection{Biodegradation Kinetic Study}

Biodegradations of phenol and PNP were carried out by using phenol- and PNPacclimated activated sludges, respectively, in a batch mode. The degradation studies were investigated by varying the initial concentrations of phenol ( 0 to $1000 \mathrm{mg} \mathrm{l}^{-1}$ ) or PNP $\left(0\right.$ to $\left.500 \mathrm{mg} \mathrm{l}^{-1}\right)$ in the presence of $400 \mathrm{mg} \mathrm{l}^{-1}$ of acclimated activated sludges and nutrients with the same composition as base mix. The residual concentration of phenol was determined using 4-aminoantipyrine method and measured spectrometrically at $506 \mathrm{~nm}$ while the PNP concentration was determined at $401 \mathrm{~nm}^{8,9}$ The biomass growth in terms of mixed liquor vapour suspended solid (MLVSS) was determined using optical density measurement at $600 \mathrm{~nm}$. The complete mineralisation of phenolic compounds was ascertained by chemical oxygen demand (COD) concentrations using closed reflux and titrimetric method. ${ }^{8}$

The specific biomass growth data was fitted into Haldane model using MATLAB software R2017a. The Haldane equation is given as below:

$$
\mu=\frac{\mu_{\max } S_{O}}{K_{s}+S_{O}+\left(\frac{S_{O}^{2}}{K_{i}}\right)}
$$

where $S_{o}$ is the initial substrate concentration $\left(\mathrm{mg}^{-1}\right), \mu_{\max }$ is the maximum specific growth rate $\left(\mathrm{h}^{-1}\right), K_{s}$ is the half-saturation constant $\left(\mathrm{mg} \mathrm{l}^{-1}\right)$ and $K_{i}$ is the substrate inhibition constant $\left(\mathrm{mg} \mathrm{l}^{-1}\right)$. The value of specific growth rate, $\mu$, was determined using a graph of biomass versus time. The kinetic data of phenolic compound degradation was fitted into pseudo zeroth-order equation shown below:

$$
[S]=\left[S_{O}\right]-k t
$$

where $S_{o}$ is the initial substrate concentration $\left(\mathrm{mg} \mathrm{l}^{-1}\right), S$ is substrate concentration at time, $t$ and $k$ is the pseudo zeroth-order rate constant. 


\section{RESULTS AND DISCUSSION}
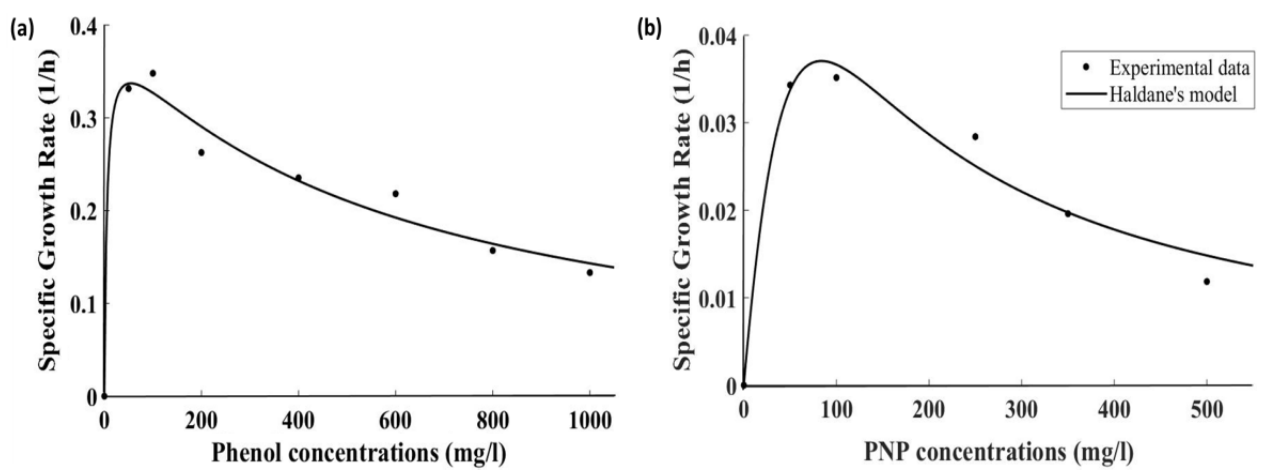

Figure 1: Experimental and Haldane predicted specific growth rates at different initial (a) phenol and (b) PNP concentrations.

Complete mineralisations of phenol and PNP were achieved as indicated by the COD concentrations below $20 \mathrm{mg} \mathrm{l}^{-1}$. The experimental data of specific growth rate was plotted against various phenol (Figure 1(a)) and PNP concentrations (Figure 1(b)). The data was observed to be well-fitted into the Haldane model. The ability of Haldane model in describing the growth kinetics in the presence of inhibitory effects was also reported in other studies. ${ }^{1,10}$ In this study, it was observed that specific growth rates, $\mu$, increased with the increase of phenol and PNP concentrations up to 100 and $50 \mathrm{mg}^{-1}$, respectively. The $\mu$ values decreased subsequently with the increase in substrate concentrations. This revealed the inhibition behaviour of phenolic compounds on acclimated activated sludges at higher concentrations. ${ }^{7,11}$

The values of kinetic parameters obtained from the fitting of Haldane model are: $\mu_{\max }=0.4039$ and $0.1346 \mathrm{~h}^{-1}, K_{s}=5.393$ and $110.3 \mathrm{mg} \mathrm{l}^{-1}, K_{i}=550.8$ and $63.58 \mathrm{mg} \mathrm{l}^{-1}$ with the $\mathrm{R}^{2}=0.9677$ and 0.9764 for phenol and PNP degradations, respectively. Based on the $K_{i}$ values obtained, the inhibition effect occurred at phenol and PNP concentrations higher than 550.8 and $63.58 \mathrm{mg} \mathrm{l}^{-1}$, respectively. Furthermore, it was reported that the degree of inhibition can be illustrated by the $K_{s} / K_{i}$ ratio, in which the resistance of acclimated activated sludge towards the inhibitory effects was indicated by a small $K_{s} / K_{i}$ ratio. ${ }^{712}$ In this study, the $K_{s} / K_{i}$ ratio for phenol degradation (0.0098) was found to be much smaller compared to that of PNP degradation (1.735). Thus, phenol-acclimated activated sludge was able to grow within the phenol concentration range studied without any observable inhibition. 
The kinetics of biodegradation of phenol and PNP fitted well to the pseudo-zerothorder equation with $\mathrm{R}^{2}$ values $>0.9$. The value of rate constant, $\mathrm{k}$, was determined from the slope of the plot of different phenol or PNP initial concentration against time and the values are presented in Table 1. For the cases of phenol biodegradation, the highest value of $\mathrm{k}$ was obtained at the initial phenol concentration of $50 \mathrm{mg} \mathrm{l}^{-1}$. This result is in agreement with the study of growth kinetics in which the $\mu_{\max }$ for phenol-acclimated activated sludge was obtained at this concentration (Figure 1(a)). In general, above $50 \mathrm{mg}^{-1}$ a gradual decrease of $\mathrm{k}$ value was observed with increasing phenol concentration. The decreasing trend is again in agreement with the Haldane fitting. For PNP biodegradation, the increasing trend of $\mathrm{k}$ values from 50 to $250 \mathrm{mg} \mathrm{l}^{-1}$ contradicts the growth kinetics results obtained using Haldane model (Figure 1(b)). Higher toxicity of PNP $\left(\mathrm{EC}_{50}=64 \mathrm{mg} \mathrm{l}^{-1}\right)$ compared to phenol $\left(\mathrm{EC}_{50}=270 \mathrm{mg} \mathrm{l}^{-1}\right)$ resulted in significant inhibitory effect at PNP concentration as low as $63.58 \mathrm{mg} \mathrm{l}^{-1}$ as predicted based on the Haldane model..$^{13}$ Thus, the use of pseudo-zeroth order equation in describing the biodegradation kinetics of PNP is not sastifactory as it does not take into account the effect of inhibition at high PNP concentration.

Table 1: Mean values of the pseudo zeroth-order rate constants for phenol and PNP biodegradations.

\begin{tabular}{cccccc}
\hline $\begin{array}{c}\text { Initial phenol } \\
\text { concentration } \\
\left(\mathrm{mg} \mathrm{l}^{-1}\right)\end{array}$ & $\begin{array}{c}\mathrm{k} \\
\left(\mathrm{mg} \mathrm{l}^{-1} \mathrm{~h}^{-1}\right)\end{array}$ & $\mathrm{R}^{2}$ & $\begin{array}{c}\text { Initial PNP } \\
\text { concentration } \\
\left(\mathrm{mg} \mathrm{l}^{-1}\right)\end{array}$ & $\begin{array}{c}\mathrm{k} \\
\left(\mathrm{mg} \mathrm{l}^{-1} \mathrm{~h}^{-1}\right)\end{array}$ & $\mathrm{R}^{2}$ \\
\hline 50 & 104.5 & 0.9486 & 50 & 13.96 & 0.9522 \\
100 & 89.1 & 0.9168 & 100 & 22.24 & 0.9307 \\
200 & 73.6 & 0.9393 & 250 & 31.18 & 0.9325 \\
400 & 63.7 & 0.9763 & 350 & 25.39 & 0.9393 \\
600 & 49.5 & 0.9732 & 500 & 16.51 & 0.9342 \\
800 & 55.8 & 0.9304 & - & - & - \\
1000 & 39.9 & 0.9425 & - & - & - \\
\hline
\end{tabular}

\section{CONCLUSION}

Specific biomass growth was well descibed by Haldane model with the kinetic parameters, $\mu_{\max }=0.4039$ and $0.1346 \mathrm{~h}^{-1}, K_{s}=5.393$ and $110.3 \mathrm{mg} \mathrm{l}^{-1}$ and $K_{s}=550.8$ and $63.58 \mathrm{mg}^{-1}$ for both phenol and PNP degradations, respectively. Low degree of inhibition for phenol biodegradation in the concentration range studied was reflected by the smaller $K_{s} / K_{i}$ ratio compared to that of PNP biodegradation. Therefore, phenol-acclimated activated sludge was able to grow 
at phenol concentration up to $1000 \mathrm{mg}^{-1}$ without experiencing inhibition. In addition, pseudo zeroth-order kinetics was used to describe the biodegradation kinetics of phenol biodegradation. However, this equation does not incorporate the inhibition effect and thus it is inadequate to explain the cases of PNP degradation at high concentrations which is attributed to its high toxicity.

\section{ACKNOWLEDGEMENTS}

The authors gratefully acknowledged the financial support from Universiti Sains Malaysia (grant number 304/PKIMIA/6313275).

\section{REFERENCES}

1. Bakhshi, Z. et al. (2011). Growth kinetic models for phenol biodegradation in a batch culture of Pseudomonas putida. Environ. Technol., 32(16), 18351841, https://doi.org/10.1080/09593330.2011.562925.

2. Jiang, Y. et al. (2010). Biodegradation of phenol and m-cresol by mutated Candida tropicalis. J. Environ. Sci., 22(4), 621-626, https://doi.org/10.1016/ S1001-0742(09)60154-6.

3. Lim, J. W., Tan, J. Z. \& Seng, C. E. (2013). Performance of phenolacclimated activated sludge in the presence of various phenolic compounds. Appl. Water Sci., 3, 515-525, https://doi.org/10.1007/s13201-013-0099-9.

4. Ahansazan, B. et al. (2014). Activated sludge process overview. Int. J. Environ. Sci. Dev., 5(1), 1-5, https://doi.org/10.7763/IJESD.2014.V5.455.

5. Lim, J. W. et al. (2013). Response of low-strength phenol-acclimated activated sludge to shock loading of high phenol concentrations. Water South Afr., 39(5), 695-700, https://doi.org/http://dx.doi.org/10.4314/wsa.v39i5.14.

6. Bhatti, Z. I., Toda, H. \& Furukawa, K. (2002). p-Nitrophenol degradation by activated sludge attached on nonwovens. Water Res., 36, 1135-1142, https://doi.org/10.1016/S0043-1354(01)00292-5.

7. Sam, S. P. \& Ng, S. L. (2017). Biodegradation of phenol by unacclimated and phenol-acclimated activated sludge: Effects of operational factors on biodegradation efficiency and kinetics. J. Phys. Sci., 28(3), 53-67, https://doi.org/10.21315/jps2017.28.3.4.

8. Rice, E. W. et al. (eds.). (2013). Standard method for the examination of water and wastewater. New York: American Public Health Association.

9. Xing, X. H. et al. (1999). Enhanced microbial adaptation to p-nitrophenol using activated sludge retained in porous carrier particles and simultaneous removal of nitrite released from degradation of p-nitrophenol. J. Biosci. Bioeng., 87(3), 372-377, https://doi.org/10.1016/S1389-1723(99)80048-6. 
10. Wei, Y. et al. (2010). Exploring kinetics of phenol biodegradation by Cupriavidus. Int. J. Mol. Sci., 11, 5065-5076, https://doi.org/10.3390/ ijms 11125065 .

11. Hussain, A., Kant, S. \& Kumar, V. (2015). Kinetic study for aerobic treatment of phenolic wastewater. Water Resour. Ind., 11, 81-90, https://doi. org/10.1016/j.wri.2015.05.002.

12. Sciences, C. et al. (2012). Studies on biodegradation of p-nitrophenol by Arthrobacter chlorophenolicus and its metabolites. Res. J. Pharm. Biol. Chem. Sci., 3(4), 695-704.

13. Gad, N. S. \& Saad, A. S. (2008). Effect of environmental pollution by phenol on some physiological parameters of oreochromis niloticus. Glob. Vet., 2(6), 312-319, https://doi.org/10.1.1.619.7089. 